\title{
ANALISIS NILAI TAMBAH PRODUK OLAHAN KENTANG (Solanum tuberosum) DI KECAMATAN CIKAJANG KABUPATEN GARUT
}

\section{ANALYSIS OF POTATO VALUE ADD (Solanum tuberosum) IN CIKAJANG SUB- DISTRICT GARUT DISTRICT}

\author{
Qisthy Arinal Haq*, Eliana Wulandari \\ Universitas Padjadjaran, Jatinangor \\ *E-mail: qisthyarinalhaq15@yahoo.com \\ (Diterima 25-01-2020; Disetujui 27-03-2020)
}

\begin{abstract}
ABSTRAK
Jumlah pengolah kentang di Kecamatan Cikajang Kabupaten Garut masih tergolong sedikit, sedangkan Kecamatan Cikajang Kabupaten Garut merupakan salah satu sentra produksi kentang yang artinya ketersediaan bahan baku melimpah dan berpotensi diolah menjadi produk lain sehingga menciptakan nilai tambah. Masalah ini disebabkan kurangnya informasi mengenai besarnya nilai tambah yang dapat diperoleh dari proses pengolahan tersebut. Oleh karena itu, tujuan penelitian ini adalah untuk menganalisis efisiensi usaha dan nilai tambah dari pengolahan kentang. Penelitian ini menggunakan desain penelitian kuantitatif dengan kuesioner sebagai instrument penelitian kepada 11 pengolah kentang di Kecamatan Cikajang Kabupaten Garut menggunakan metode sensus pada bulan September-November 2019. Sumber data yang digunakan adalah data primer dan sekunder. Data yang terkumpul diolah menggunakan metode analisis efisiensi usaha ( $\mathrm{RC}$ ratio) dan metode Hayami. Hasil penelitian menunjukkan bahwa efisiensi usaha pengolahan kentang menjadi keripik kentang di Kecamatan Cikajang sebesar 1,8; dan nilai tambah yang diperoleh sebesar Rp 10.647,4/kg bahan baku kentang dengan rasio nilai tambah $48,04 \%$.
\end{abstract}

Kata kunci: nilai tambah, metode Hayami, kentang, efisiensi usaha, RC rasio

\section{ABSTRACT}

The number of potato processors in Cikajang Sub-district Garut District is still relatively small, while Cikajang Sub-district Garut District is one of the production centers of potato commodities, which means the availability of abundant raw materials and has potential to be processed into other products to create added value. This problem can be caused by lack of information regarding the amount of added value that can be obtained from the processing. Therefore, the purpose of this study is to analyze the business efficiency and added value of potato processing. This study uses a quantitative research design with a questionnaire as a research instrument to 11 potato processors in Cikajang Sub-district, Garut District using the census method in September - November 2019. Data sources used are primary and secondary data. The data collected was processed using the business efficiency analysis method (RC ratio) and Hayami method. The results showed that the efficiency of processing potatoes into potato chips in Cikajang Sub-district was 1.8 and the added value obtained was $R p 10,647.4$ / $\mathrm{kg}$ of potato raw material with a value-added ratio of $48.04 \%$.

Keywords: added value, hayami method, potatoes, business efficiency, $R C$ ratio

\section{PENDAHULUAN}

Sektor industri pengolahan

merupakan salah satu kontributor terbesar dalam pertumbuhan ekonomi Indonesia terhadap Produk Domestik Bruto (PDB). Badan Pusat Statistik (BPS) menyatakan 
pada tahun 2018 perekonomian Indonesia tumbuh lebih tinggi dari tahun sebelumnya sebanyak 5,17 persen, sumber pertumbuhan PDB tersebut menurut lapangan usaha berasal dari beberapa sektor yaitu industri pengolahan yang menyumbang $0,91 \%$ terhadap PDB, perdagangan besar-eceran $0,66 \%$; konstruksi $0,61 \%$; pertanian, kehutanan dan perikanan $0,50 \%$; informasi dan komunikasi $0,36 \%$, sedangkan dari sektor lainnya 2,14\% (Badan Pusat Statistik, 2019).

Agroindustri merupakan salah satu sektor industri pengolahan yang mengolah hasil pertanian, dan dari kegiatan tersebut akan meningkatkan pendapatan yang kemudian berakibat pada peningkatan permintaan, perkembangan pasar, tenaga kerja, serta dapat menarik perkembangan sektor pertanian. Salah satu agroindustri yang memiliki potensi untuk dikembangkan adalah industri pengolahan makanan (Badan Pusat Statistik, 2018).

Kentang merupakan salah satu tanaman hortikultura yang mengandung karbohidrat dan dapat dijadikan sebagai bahan baku agroindustri. Umumnya kentang dijual dalam bentuk segar atau olahan, pemanfaatan kentang dalam bentuk olahan dapat berupa keripik

kentang, sambal goreng kentang, kentang goreng, tepung kentang dan sebagainya (Udayana, 2011). Tujuan pengolahan adalah untuk meningkatkan keawetan, mengingat bahwa sebagai produk pertanian kentang seringkali mengalami kerusakan baik saat penanaman, pemanenan, maupun penyimpanan yang dapat menurunkan kualitas kentang, selain itu juga pengolahan dilakukan agar memperoleh nilai jual yang lebih tinggi di pasaran (Alifia, 2012).

$$
\text { Jawa Barat merupakan daerah }
$$
sentra produksi terbesar nasional khususnya di daerah Kabupaten Garut, Kecamatan Cikajang sebagaimana terlihat pada Tabel 1.

Tabel 1. Produksi kentang di Kabupaten Garut (2017)

\begin{tabular}{lc}
\hline \multicolumn{1}{c}{ Kecamatan } & Produksi kentang (kg) \\
\hline Talegong & 144 \\
Pamulihan & 5.894 \\
Cikajang & 27.904 \\
Banjarwangi & 3.530 \\
Cilawu & 4.393 \\
Bayongbong & 4.563 \\
Cigedug & 16.694 \\
Cisurupan & 27.214 \\
Sukaresmi & 25.374 \\
Samarang & 2.893 \\
Pasirwangi & 51.529 \\
Sumber: (Badan Pusat Statistik, 2017) \\
\multicolumn{2}{c}{ Tabel 1 menunjukkan bahwa } \\
produksi kentang di Kabupaten Garut \\
sangat melimpah. Industri pengolahan \\
kentang merupakan salah satu industri \\
yang saat ini sedang dikembangkan di \\
Kecamatan Cikajang Kegiatan dalam
\end{tabular}


industri yang mengubah bentuk primer menjadi produk baru akan mengalami peningkatan nilai ekonomisnya, hal ini disebabkan oleh proses pengolahan yang menambahkan input-input produksi sehingga dikeluarkan biaya-biaya lain dan terbentuk biaya baru yang lebih tinggi, dan juga menghasilkan keuntungan yang lebih besar jika dibandingkan dengan produk mentah tanpa proses pengolahan. Namun, jumlah pengolah kentang di Kecamatan Cikajang Kabupaten Garut masih tergolong sedikit, hal ini disebabkan kurangnya informasi mengenai besarnya nilai tambah yang dapat diperoleh dari proses pengolahan. Oleh karena itu, diperlukan analisis mengenai besarnya nilai tambah yang didapat dari hasil pengolahan kentang menjadi keripik.

\section{METODE PENELITIAN}

Penelitian ini dilaksanakan di Kecamatan Cikajang Kabupaten Garut pada bulan September-November 2019. Penentuan lokasi tersebut dipilih karena merupakan salah satu sentra produksi kentang di Jawa Barat. Jenis penelitian yang digunakan adalah kuantitatif. Penelitian kuantitatif merupakan suatu cara yang digunakan untuk menjawab masalah penelitian yang berkaitan dengan data berupa angka dan program statistik untuk dapat menjabarkan dengan baik tentang pendekatan dan jenis penelitian, populasi dan sampel, instrumen penelitian, teknik pengumpulan data, dan analisis data dalam suatu proposal dan/atau laporan penelitian diperlukan pemahaman yang baik tentang masingmasing konsep tersebut (Sugiyono, 2016).

Metode pengumpulan data dalam penelitian ini adalah dengan kuesioner, wawancara dengan responden, dan studi kepustakaan. Sumber data yang digunakan adalah data primer dan sekunder. Data primer merupakan data yang diperoleh secara langsung dengan cara pengisian kuesioner dan wawancara terhadap 11 responden pengolah kentang di Kecamatan Cikajang menggunakan teknik sensus. Sedangkan data sekunder didapat dari instansi terkait, dalam penelitian ini instansi yang terkait adalah Badan Pusat Statistik dan Dinas Perdagangan dan UMKM Kabupaten Garut.

Metode analisis data yang digunakan dalam penelitian ini adalah statistika deskriptif untuk membuat gambaran secara akurat mengenai pengolahan kentang yang dilakukan oleh pengolah kentang di Kecamatan 
Cikajang, Kabupaten Garut dengan cara menganalisis data dan mendekripsikannya. Adapun alat analisis yang digunakan adalah $\mathrm{RC}$ rasio untuk mengetahui efisiensi usaha pengolahan kentang. Secara sistematis rumus RC rasio dapat ditulis sebagai berikut:

$$
\mathrm{RC} \text { rasio }=\frac{\text { Penerimaan }}{\text { Biaya Total }}
$$

Sedangkan alat analisis untuk mengitung nilai tambah (Tabel 2) pada suatu produk adalah dengan menggunakan metode Hayami. Besarnya nilai tambah yang dihasilkan dapat diperkirakan nilainya berdasarkan balas jasa yang diterima oleh pemilik usaha dalam proses pengolahan atas biayabiaya yang dikeluatkan. Terdapat tiga komponen pendukung dalam analisis nilai tambah, yaitu pertama, faktor konversi yang menunjukkan besarnya output yang dihasilkan dari satu-satuan input. Kedua, koefisien tenaga kerja yang menunjukkan tenaga kerja yang dibutuhkan untuk mengolah satu-satuan input. Ketiga, nilai produk yang menunjukkan nilai output dari setiap hasil pengolahan satu-satuan input.

Tabel 2. Metode Hayami

\begin{tabular}{lcc}
\hline \multicolumn{1}{c}{ Variabel } & Satuan & Nilai \\
\hline I. Output, Input dan Harga & & $\mathrm{A}$ \\
\hline Output yang dihasilkan & $\mathrm{Kg} /$ periode & $\mathrm{B}$ \\
Bahan baku yang digunakan & $\mathrm{Kg} /$ periode & $\mathrm{C}$ \\
Tenaga Kerja & $\mathrm{HOK} /$ periode & $\mathrm{D}=\mathrm{A} / \mathrm{B}$ \\
Faktor konversi & & $\mathrm{E}=\mathrm{C} / \mathrm{B}$ \\
Koefisien tenaga kerja & $\mathrm{Fp} / \mathrm{Kg}$ \\
Harga Output & $\mathrm{Rp} / \mathrm{HOK}$ & $\mathrm{G}$ \\
Upah rata-rata tenaga kerja, Pendapatan dan Keuntungan & & $\mathrm{H}$ \\
\hline II. Penerimaan dan Keuntungan & $\mathrm{Rp} / \mathrm{Kg}$ & $\mathrm{I}$ \\
\hline Harga bahan baku & $\mathrm{Rp} / \mathrm{Kg}$ & $\mathrm{J}=\mathrm{D} \times \mathrm{F}$ \\
Sumbangan Input Lain & $\mathrm{Rp} / \mathrm{Kg}$ & $\mathrm{K}=\mathrm{J}-\mathrm{H}-\mathrm{I}$ \\
Nilai Output & $\mathrm{Rp} / \mathrm{Kg}$ & $\mathrm{L}(\%)=\mathrm{K} / \mathrm{J}(\%)$ \\
Nilai Tambah & $\%$ & $\mathrm{M}=\mathrm{E} \times \mathrm{G}$ \\
Rasio Nilai Tambah & $\mathrm{Rp} / \mathrm{Kg}$ & $\mathrm{N}(\%)=\mathrm{N} / \mathrm{K}(\%)$ \\
Imbalan Tenaga Kerja & $\%$ & $\mathrm{O}=\mathrm{K}-\mathrm{M}$ \\
Bagian Tenaga Kerja & $\mathrm{Rp} / \mathrm{kg}$ & $\mathrm{P}(\%)=\mathrm{O} / \mathrm{K}(\%)$ \\
Keuntungan & $\%$ & \\
Tingkat Keuntungan & & \\
\hline
\end{tabular}

\section{HASIL DAN PEMBAHASAN}

Kecamatan Cikajang adalah salah satu kecamatan yang ada di Kabupaten Garut, mayoritas penduduknya memiliki mata pencaharian sebagai yaitu sebanyak
$62,5 \%$, sedangkan sisanya bekerja di bidang industri, pertambangan dan penggalian, konstruksi, dan lainnya.

Kentang merupakan komoditas hortikultura utama di Kecamatan 
Cikajang yang jumlah produksinya mencapai 27.904 ton, dengan luas panen 1.442 Ha pada tahun 2017.

Kentang dapat tumbuh dengan baik di wilayah tersebut karena kondisi topografinya sesuai dengan syarat tumbuh, sehingga kentang dapat tumbuh dengan subur. Melimpahnya produksi kentang menjadi sebuah peluang untuk berkembangnya sektor industri pengolahan makanan yang berbahan dasar kentang. Menurut data Dinas Industri dan Perdagangan Kabupaten Garut (2018), jumlah industri kecil menengah bidang industri agro di Kecamatan Cikajang berjumlah 43 usaha. Usaha pengolahan kentang di daerah Cikajang ini spesifik mengolah kentang menjadi keripik dengan jumlah total 11 usaha pengolah kentang. Selain itu, juga terdapat berbagai usaha pengolahan makanan lainnya seperti manisan, gula, kerupuk, tempe, tahu, dan lainnya.

Penelitian ini dilakukan pada 11 responden yang menjadi pengolah kentang khususnya mengolah kentang menjadi keripik di Kecamatan Cikajang Kabupaten Garut. Responden berada dalam rentang umur 31-51 tahun, tingkat pendidikan formal pengolah kentang beragam mulai dari S1 (18,18\%), SMA $(72,72 \%), \quad$ dan $\quad$ SMP $\quad(9,10 \%)$.
Berdasarkan hasil wawancara juga menyatakan 11 responden sudah memiliki izin resmi dari Dinas Kesehatan dan sudah memiliki merk dagang.

Pengolah yang memiliki pengalaman usaha lebih lama maka lebih banyak juga ilmu dan pengetahuan yang didapat, sehingga dapat mengatasi masalah-masalah yang dihadapi secara rasional dibandingkan pengolah yang kurang berpengalaman. Tabel 3 menunjukan pengalaman pengolah dalam tahun.

Tabel 3. Karakteristik responden berdasarkan pengalaman mengolah kentang

\begin{tabular}{ccc}
$\begin{array}{c}\text { Pengalaman } \\
\text { (tahun) }\end{array}$ & $\begin{array}{c}\text { Jumlah } \\
\text { Responden } \\
\text { (orang) }\end{array}$ & $\begin{array}{c}\text { Persentase } \\
(\%)\end{array}$ \\
\hline $0-5$ & 5 & 45,45 \\
$6-10$ & 4 & 36,37 \\
$11-15$ & - & - \\
$16-20$ & 2 & 18,18 \\
\hline Total & 11 & 100 \\
\hline
\end{tabular}

Pengadaan faktor produksi dalam kegiatan usaha mengolah kentang menjadi keripik kentang di Kecamatan Cikajang pada dasarnya menggunakan bahan baku yang sama di setiap pengolah, yaitu kentang dengan varietas atlantik. Kentang varietas ini memiliki umbi berwarna putih, umumnya berbentuk bulat dengan kandungan 20-22 persen total padatan dan memiliki kadar gula yang rendah. Bahan baku ini biasanya dikirim langsung oleh petani sekitar tempat usaha yang sudah menjadi 
langganan. Harga yang diberikan petani berada pada rentang $\mathrm{Rp} 9.000$ - Rp 9.500 dengan rata-rata harga $\mathrm{Rp} \quad 9.318,2$ tergantung pada intensitas dan kuantitas pembelian kepada petani. Kuantitas kentang yang dibeli dari petani sekitar 200-1.000 kg, dengan rata-rata banyaknya yaitu 490,9 kg. Berdasarkan hasil wawancara kepada responden diketahui bahwa banyaknya pengolahan kentang yang dilakukan minimum sebanyak $200 \quad \mathrm{~kg}$ karena adanya penyusutan akibat penggorengan atau pemanasan sebanyak $70-75 \%$ pada keripik kentang sehingga jika produksi dilakukan di bawah jumlah minimum maka tidak akan mendapat keuntungan. Data tersebut didapat oleh responden dari pengalaman pribadi serta seminar dan pelatihan yang diadakan oleh dinas pertanian Kabupaten Garut. Sedangkan untuk bahan tambahan yang digunakan yaitu garam, penyedap rasa, minyak goreng, kayu bakar/tabung gas, dan kemasan. Dua dari sebelas responden menggunakan kayu sebagai bahan bakar yang didapat dari sekitar unit pengolahan, sedangkan sisanya menggunakan gas LPG. Biasanya pengolah membeli kayu bakar dengan ukuran per mobil atau sekitar 12 kubik dengan harga $\mathrm{Rp}$ 1.200.000/mobil atau 100.000/kubik.

Peralatan yang digunakan selama proses produksi diantaranya pisau, alat pengupas, slicer atau alat pemotong, wajan, kompor, pengaduk, wadah, sealer dan lainnya. Terdapat beberapa mesin yang didapat dari bantuan pemerintah seperti mesin pemotong atau slicer dan mesin pengupas untuk beberapa orang responden. Alat yang digunakan untuk mengaduk dibuat sendiri dan dipesan khusus namun ada juga yang membelinya di pasar. Peralatan lainnya bisa dengan mudah didapatkan di pasar-pasar sekitar unit pengolahan. Bangunan yang dipakai sebagai tempat unit usaha adalah rumah dari pemilik usaha tersebut namun tetap perlu diperhitungkan sebagai biaya tetap yang dikeluarkan per tahunnya. Oleh karena itu harga bangunan ditetapkan berdasarkan pada harga sewa di lingkungan sekitar usaha pengolahan keripik kentang per tahunnya dengan pertimbangan bahwa tidak seluruh bagian rumah dijadikan sebagai tempat produksi atau hanya sebagian ruangan tertentu saja. Harga sewa bangunan di Kecamatan Cikajang Kabupaten Garut berada di kisaran Rp 4.500.000 - Rp 6.500.000 per tahunnya. 
Tabel 4. Jenis dan nilai penyusutan peralatan pada pengolahan keripik kentang

\begin{tabular}{lrcrr}
\hline Jenis Alat & Nilai Awal (Rp) & Umur Ekonomis (Tahun) & Nilai Akhir (Rp) & Penyusutan (Rp) \\
\hline Kompor & 1.100 .000 & 13 & $84.615,4$ & $78.106,5$ \\
Slicer & 20.000 .000 & 20 & 1.000 .000 & 950.000 \\
Pisau & 14.136 & 4 & 3.534 & $2.650,5$ \\
Wajan & 3.645 .400 & 17 & $214.435,3$ & $201.821,5$ \\
Mesin pengupas & 7.272 .000 & 7 & $1.038 .857,1$ & 890.449 \\
Tong & 81.800 & 6 & $13.633,3$ & $11.361,1$ \\
Pengaduk & 70.500 & 6 & 11.750 & $9.791,7$ \\
Meja sortir & 2.727 .300 & 5 & 545.460 & 436.368 \\
Sealer & 1.402 .300 & 15 & $93.486,7$ & $87.254,2$ \\
Wadah & 35.900 & 5 & 7.180 & 5.744 \\
Ember & 67.700 & 6 & $11.283,3$ & $9.402,8$ \\
Bangunan & 5.363 .000 & 1 & 5.363 .000 & 5.363 .600 \\
\hline Jumlah & 41.780 .636 & & 8.387 .8351 & 7.097 .499 .3 \\
\hline
\end{tabular}

Faktor produksi lainnya adalah tenaga kerja dan transportasi. Di Kecamatan Cikajang Kabupaten Garut biaya Harian Orang Kerja (HOK) berada di kisaran Rp 35.000 - Rp 50.000, banyaknya pengolah di setiap unit usaha berbeda-beda tergantung pada seberapa banyak output yang akan diperoleh. Ratarata tenaga kerja yang digunakan, yaitu sebanyak 3 orang dengan rentang 2-5 orang pada setiap unit usaha. Sedangkan untuk transportasi kebanyakan responden tidak melakukan pengiriman atau pengambilan secara rutin karena kebanyakan bahan baku produksi dikirim oleh petani langsung dan output keripik kentang diambil sendiri oleh konsumen. Namun, jika ada pesanan khusus keluar kota maka biaya transportasinya berkisar Rp 600.000 - Rp 1.000.000 dalam sekali pengiriman.

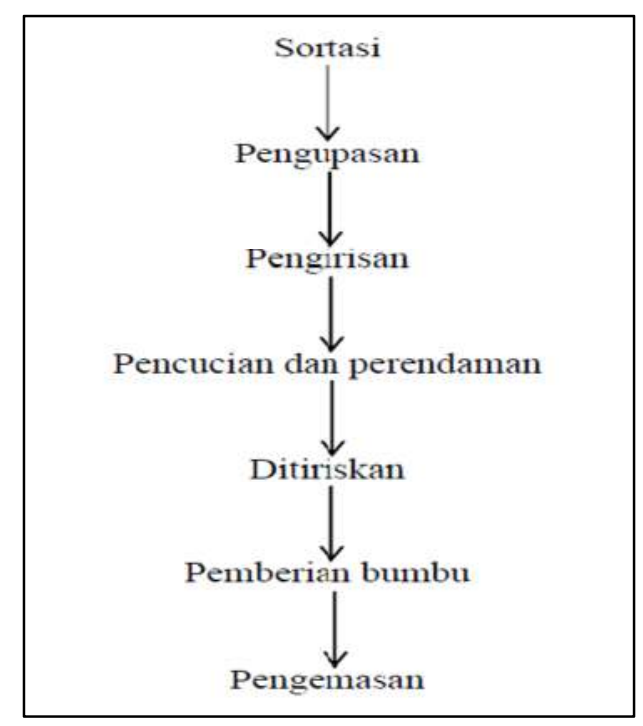

Gambar 1. Proses pengolahan keripik kentang

Pemasaran yang dilakukan oleh responden pemilik usaha keripik kentang di Kecamatan Cikajang Kabupaten Garut untuk memasarkan produknya yaitu dengan cara menyalurkan langsung ke pedagang, baik yang berada di sekitar usaha. maupun di luar kota seperti Bandung, Semarang, dan Yogyakarta. Beberapa responden dengan kapasitas olahan $\geq 1000 \mathrm{~kg} /$ hari rata-rata sudah memiliki pasar tetap di luar kota. 
Analisis biaya digunakan untuk menghitung biaya tetap, biaya variabel dan biaya total usaha pengolahan kentang dalam proses pembuatannya. Tujuan dari analisis biaya adalah untuk menggolongkan biaya berdasarkan fungsi pokok dalam usaha dan perilakunya dalam perubahan volume kegiatan pengolahan.

Tabel 5. Biaya variabel dalam satu kali pengolahan kentang

\begin{tabular}{|c|c|c|c|}
\hline Jenis & Satuan & Fisik & $\begin{array}{c}\text { Jumlah } \\
\text { Harga (Rp) }\end{array}$ \\
\hline \multicolumn{4}{|l|}{$\begin{array}{l}\text { Bahan baku } \\
\text { utama: }\end{array}$} \\
\hline Kentang & $\mathrm{Kg}$ & 490,9 & $4.574 .304,4$ \\
\hline \multicolumn{3}{|c|}{ Jumlah } & $4.574 .304,4$ \\
\hline \multicolumn{4}{|c|}{ Bahan penolong } \\
\hline Garam & $\mathrm{Kg}$ & 0,3 & $2.245,5$ \\
\hline Penyedap rasa & $\mathrm{Kg}$ & 0,3 & $6.581,8$ \\
\hline Minyak goreng & $\mathrm{Kg}$ & 37,1 & $448.909,1$ \\
\hline Kayu bakar & Kubik & 0,5 & $54.545,5$ \\
\hline Gas LPG & $\mathrm{Kg}$ & 27,8 & $255.136,4$ \\
\hline Kemasan & $\mathrm{Kg}$ & 1,1 & 33.750 \\
\hline \multicolumn{3}{|c|}{ Jumlah } & $801.168,3$ \\
\hline \multicolumn{4}{|l|}{ Biaya } \\
\hline Tenaga kerja & $\mathrm{HOK}$ & 3 & $130.227,3$ \\
\hline Transportasi & & & $145.454,5$ \\
\hline \multicolumn{3}{|c|}{ Jumlah } & $275.681,8$ \\
\hline \multicolumn{3}{|c|}{ Total Biaya Variabel } & $5.651 .154,5$ \\
\hline
\end{tabular}

Tabel 6. Biaya total dalam satu kali pengolahan kentang

\begin{tabular}{crc}
\hline Jenis biaya & $\begin{array}{c}\text { Jumlah } \\
\text { (Rp/Produksi) }\end{array}$ & $\begin{array}{c}\text { Persenta } \\
\text { se (\%) }\end{array}$ \\
\hline Biaya tetap & $19.715,3$ & 0,35 \\
Biaya variabel & $5.651 .154,5$ & 99,65 \\
\hline Biaya Total & $\mathbf{5 . 6 7 0 . 8 6 9 , 8}$ & $\mathbf{1 0 0}$ \\
\hline
\end{tabular}

Efisiensi usaha pengolahan kentang menjadi keripik kentang dapat dihitung menggunakan analisis $\mathrm{RC}$ rasio yang merupakan perbandingan antara penerimaan dengan biaya total.
Tabel 7. Analisis efisiensi usaha pengolahan kentang

\begin{tabular}{llc}
\multicolumn{3}{c}{ kentang } \\
\hline No & \multicolumn{1}{c}{ Uraian } & Jumlah (Rp) \\
\hline 1. & Penerimaan total (R) & $9.971 .640,0$ \\
2. & Biaya total (C) & $5.670 .869,8$ \\
\hline & Efisiensi (R/C) & $\mathbf{1 , 8}$ \\
\hline
\end{tabular}

Analisis nilai tambah pada 11 unit usaha pengolahan kentang menjadi keripik bertujuan untuk mengetahui ratarata nilai yang ditambahkan pada proses pengolahan dan bahan baku sebagai biaya antara untuk memproduksi keripik kentang. Hasil perhitungan nilai tambah pada Tabel 8 menunjukkan bahan baku yang digunakan dalam satu kali proses produksi adalah 490,9 $\mathrm{kg}$ yang menghasilkan $135 \mathrm{~kg}$ keripik kentang. Rata-rata tenaga kerja yang digunakan dalam proses pengolahan sebanyak 3 orang.

Faktor konversi adalah suatu rasio antara hasil pengolahan dengan jumlah bahan baku yang digunakan dengan nilai konversi 0,3. Maksudnya setiap satu kilogram kentang yang diolah akan diperoleh $0,3 \mathrm{~kg}$ keripik kentang. Nilai koefisen tenaga kerja yaitu 0,006 yang didapat dari hasil perbandingan tenaga kerja dengan pengolahan bahan baku, artinya setiap tenaga kerja mampu mengolah bahan baku sebanyak 0,006 kg setiap $1 \mathrm{~kg}$ kentang.

Harga jual rata-rata keripik kentang adalah Rp 73.864/kg sedangkan harga 
bahan baku kentang rata-rata sebesar $\mathrm{Rp}$ $9.318,2 / \mathrm{kg}$. Sumbangan input lain atau bahan penolong dan biaya operasional bernilai Rp 2.193,6/kg. Adapun nilai output diperoleh dari perkalian antara faktor konversi dengan harga output yang hasilnya adalah $\mathrm{Rp} 22.159,2 / \mathrm{kg}$ bahan baku. Nilai tambah yang diperoleh dari hasil pengolahan sebesar Rp 10.647,4/kg bahan baku, jumlah tersebut didapat dari hasil selisih antara nilai produk dengan harga bahan baku dan sumbangan input lain. Rasio nilai tambah terhadap nilai output adalah 48,04\%, angka ini menunjukkan bahwa setiap Rp 100 nilai produk mentah maka akan diperoleh nilai tambah sebanyak Rp 48,04.

Imbalan tenaga kerja diperoleh dari perkalian antara koefisien tenaga kerja dengan upah rata-rata yaitu $\mathrm{Rp} 781,4 / \mathrm{kg}$ bahan baku. Bagian tenaga kerja adalah perbandingan antara imbalan tenaga kerja dengan nilai tambah yang bernilai 7,3\%. Keuntungan yang didapat dari pengolahan kentang menjadi keripik sebesar Rp 9.866/kg bahan baku. Jika ditunjukkan dalam bentuk persentase maka angka yang dicapai untuk keuntungan yang diperoleh adalah 92,7\%. Hasil ini dapat menguntungkan usaha pengolah kentang menjadi keripik kentang di Kecamatan Cikajang
Kabupaten Garut. Namun demikian pengolah kentang di Kecamatan Cikajang masih tergolong sedikit.

Tabel 8. Analisis nilai tambah dalam satu kali pengolahan kentang

\begin{tabular}{lcc}
\hline Variabel & Satuan & Nilai \\
\hline I. Output, Input dan Harga & & \\
\hline Output yang dihasilkan & $\mathrm{Kg} / \mathrm{p}$ eriode & 135 \\
Bahan baku yang digunakan & $\mathrm{Kg} / \mathrm{p}$ eriode & 490,9 \\
Tenaga Kerja & $\mathrm{HOK} /$ periode & 3 \\
Faktor konversi & & 0,3 \\
Koefisien tenaga kerja & & 0,006 \\
Harga Output & $\mathrm{Rp} / \mathrm{Kg}$ & 73.864 \\
Upah rata-rata tenaga kerja & $\mathrm{Rp} / \mathrm{HOK}$ & $130.227,3$ \\
\hline II. Penerimaan dan Keuntungan & & \\
\hline Harga bahan baku & $\mathrm{Rp} / \mathrm{Kg}$ & $9.318,2$ \\
Sumbangan Input Lain & $\mathrm{Rp} / \mathrm{Kg}$ & $2.193,6$ \\
Nilai Output & $\mathrm{Rp} / \mathrm{Kg}$ & $22.159,2$ \\
Nilai Tambah & $\mathrm{Rp} / \mathrm{Kg}$ & $10.647,4$ \\
Rasio Nilai Tambah & $\%$ & 48,04 \\
Imbalan Tenaga Kerja & $\mathrm{Rp} / \mathrm{Kg}$ & 781,4 \\
Bagian Tenaga Kerja & $\%$ & 7,3 \\
Keuntungan & $\mathrm{Rp} / \mathrm{kg}$ & 9.866 \\
Tingkat Keuntungan & $\%$ & 92,7 \\
\hline
\end{tabular}

\section{KESIMPULAN DAN SARAN}

Nilai efisiensi usaha pengolahan kentang menjadi keripik kentang adalah sebesar 1,8. Angka tersebut menunjukkan lebih besar dari 1 yang artinya usaha pengolahan keripik kentang sudah efisien. Pengolahan keripik kentang memperoleh nilai tambah sebesar $\mathrm{Rp}$ $10.647,40 / \mathrm{kg}$ bahan baku kentang dengan rasio nilai tambah $48,04 \%$, artinya untuk setiap Rp 100,00 nilai produk mentah maka dapat memberikan nilai tambah sebanyak Rp 48,04. Nilai tambah tenaga kerja yang diperoleh, yaitu $\mathrm{Rp} 781,40 / \mathrm{kg}$ bahan baku. Keripik kentang bisa bertahan selama sekitar 3 bulan, adapun 
harga jual rata-rata untuk keripik kentang per kilogramnya adalah $\mathrm{Rp} 73.864,00$.

\section{UCAPAN TERIMA KASIH}

Terimakasih penulis ucapkan kepada seluruh pengolah kentang di Kecamatan Cikajang Kabupaten Garut. Terimakasih pula penulis ucapkan kepada Badan Pusat Statistik dan Dinas Perdagangan dan UMKM Kabupaten Garut yang telah membantu data sekunder berupa literatur yang digunakan dalam penelitian.

\section{DAFTAR PUSTAKA}

Alifia. F D. (2012). Pengembangan agroindustri sangko di Kecamatan Sapekan Kabupaten Sumenep. JSEP 6(3), 64-71.

Badan Pusat Statistik. (2017). Produk Domestik Bruto Indonesia Triwulanan 2014-2018. Diakses pada tanggal 20 Juli 2019.

Badan Pusat Statistik. (2019). Pertumbuhan Ekonomi Indonesia Triwulan IV-2018 No. 15/02/Th.XXII. diakses pada tanggal 20 Juli 2019.

Sugiyono. (2016). Metode Penelitian \& Pengembangan: Research and development. Cetakan ke 3. Jakarta.

Udayana, I. G. B. (2011). Peran agroindustri dalam pembangunan pertanian. 3-8. Jakarta. 